\title{
Impact of Copper Doping on the Structural, Electrical and Optical Properties of Auto-Combustion Synthesized ZnO Nanocomposites
}

\author{
M.F. MAnzoor ${ }^{a}$, E. Ahmad ${ }^{a}$, M. Ullah ${ }^{a, *}$, A.M. RAna ${ }^{a}$, A.S. MAlik ${ }^{b}$, M. FArooq $^{c}$,

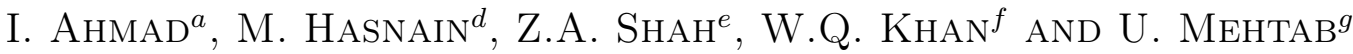 \\ ${ }^{a}$ Department of Physics, Bahauddin Zakariya University, Multan, 60800, Pakistan \\ ${ }^{b}$ Department of Electrical Engineering, Bahauddin Zakariya University, Multan, 60800, Pakistan \\ ${ }^{c}$ Directorate of Quality Enhancement, Bahauddin Zakariya University, Multan, 60800, Pakistan \\ ${ }^{d}$ Institute of Chemical Science, Bahauddin Zakariya University, Multan, 60800, Pakistan \\ ${ }^{e}$ Department of Basic Sciences and Humanities, Khawaja Fareed University of Engineering \\ and Information Technology, Rahim Yar Khan, 64200 Pakistan \\ ${ }^{f}$ Institute of Advanced Materials, Bahauddin Zakariya University, Multan, 60800, Pakistan \\ ${ }^{g}$ Department of Pathobiology, Faculty of Veterinary Sciences, B.Z. University Multan, Pakistan
}

(Received August 20, 2018; in final form January 21, 2019)

\begin{abstract}
Nanocomposites of $\mathrm{ZnO}$ have been synthesized by auto-combustion technique to study their electrical (dielectric and direct current), optical, and structural properties by increasing copper content in these composites. Techniques used for characterizing these composite nanoparticles involve X-ray diffraction, scanning electron microscopy, UV-vis spectrophotometry, and photoluminescence spectroscopy. X-ray diffraction patterns suggested hexagonal wurtzite structure of $\mathrm{ZnO}$, which remains unchanged upon increasing the amount of $\mathrm{Cu}$ dopant. However, there is a noticeable decrease in the particle size with rising $\mathrm{Cu}$ content. Morphology of the crystallites, as observed by scanning electron microscopy, is nearly spherical. Dielectric parameters, including dielectric constant and dielectric loss, decrease, whilst AC conductivity increases with the increase of $\mathrm{Cu}$ content as well as with the rise of frequency of the applied alternating biasing field. In addition, DC electrical conductivity is also improved by the enhancement of $\mathrm{Cu}$ doping percentage and temperature. These variations of electrical parameters of nanocomposites allow their potential utilization in those devices which are operated at high frequencies. Band gap energy $E_{g}$, analyzed by UV-vis spectrophotometer, is noticed to decrease upon rising Cu content from $3.39 \mathrm{eV}$ to $2.46 \mathrm{eV}$, and depicts a red shift from UV to visible light region. PL emission intensity decreased in the studied light spectrum by increasing $\mathrm{Cu}$ content implying that the recombination rate of photo-induced charge carriers decreases effectively. Thus, upon $\mathrm{Cu}$ doping reduction in $E_{g}$ occurs, which along with the reduced recombination rates of photogenerated electrons and holes pairs, becomes a cause of the participation of more and more charge carriers in the photocatalysis process in order to degrade the organic compounds.
\end{abstract}

DOI: 10.12693/APhysPolA.135.458

PACS/topics: $\mathrm{Cu}$ doped $\mathrm{ZnO}$, XRD, SEM, DRS, PL, electrical properties, optical properties

\section{Introduction}

The particle size of nanocomposite materials in general lies between $1 \mathrm{~nm}$ and $100 \mathrm{~nm}$. Due to this nanosize of particles, variations in the band-gap energy are expected, which might become responsible for the electrical and optical properties suitable for optoelectronics devices. Moreover, applications of semiconducting materials such as $\mathrm{ZnO}, \mathrm{SnO}_{2}$, and $\mathrm{TiO}_{2}$ may be enhanced by doping [1-8]. Among these, $\mathrm{ZnO}$ has many potential applications such as varistors [9], solar cells [10], light emitting devices [11], for photocatalysis [12], and cancer treatment [13]. As $\mathrm{ZnO}$ possesses significant magnitude (about $60 \mathrm{meV}$ ) of exciton binding energy of vitality in comparison to other semiconductors such as $\mathrm{TiO}_{2}$, its wide band gap $E_{g}$ of $3.37 \mathrm{eV}$ (at room temperature)

\footnotetext{
* corresponding author
}

also escalates its activity $[14,15]$. In addition, low cost, non-toxicity, excellent chemical and mechanical stability make $\mathrm{ZnO}$ an ideal semiconductor $[16,17]$. Current density caused by the minority charge carriers can be increased or decreased by dopants on developing grain edges, which also cause an increase in the non-linear coefficient $a$. Some dopants increase the non-linear coefficient by prohibiting the growth of grain boundaries whereas some other dopants improve the electrical properties by decreasing the resistivity and increasing the current density [18-21]. The dopants, like transition metals (i.e. Co, $\mathrm{Fe}, \mathrm{Ni}$, and $\mathrm{Cu}$ ), assist in enhancing the non-linear coefficient $[22,23]$.

In addition to the electrical properties, photocatalytic characteristics of $\mathrm{ZnO}$ have been deliberated for encountering the worldwide energy deficit as well as environmental crises in the presence of solar light. Rapid industrialization and development during previous decades have drawn the attention of environmental 
photocatalysts for water and air sanitization, perilous waste rectification, depolarization, antibacterial, and water decontamination. Due to antibacterial, antineoplastic, wound healing, ultraviolet scattering, and angiogenic properties, $\mathrm{ZnO}$ nanoparticles have applications also in animal health and production [24]. Researchers have noticed that $\mathrm{ZnO}$ possesses effective photocatalytic efficiency under the irradiation of UV-light because of its wide band gap. The formation of hydroxyl radical ions near the surface of $\mathrm{ZnO}$ nanocomposites assists in the degradation of organic pollutants present around it. These radical ions are created as a result of the irradiation of light of suitable wavelength on $\mathrm{ZnO}$. Such irradiation might become a cause of the valence band potential to become sufficiently large in positivity needed for the creation of hydroxyl radicals on the surface, which in turn reduce the formation of molecular oxygen due to the sufficiently large negativity of conduction band [25-32]. Further, fast recombination of photo-induced charge carriers reduces the efficiency of intrinsic $\mathrm{ZnO}$, therefore to improve its activity $\mathrm{ZnO}$ can be doped with metals. The dopants generate traps by creating impurity states in the energy band gap. These traps reduce the recombination rate of photo-induced charge carriers, which consequently enhance the photocatalytic efficiency of $\mathrm{ZnO}$ nanocomposites [30, 32, 33].

There are so many different techniques for synthesizing the $\mathrm{ZnO}$ nanoparticles, which include sol-gel, chemical vapor deposition [34], thermal deposition [35], spray pyrolysis, precipitation, hydrothermal fabrication [36], co-precipitation [37], and auto-combustion method [38]. Amongst these diverse approaches, auto-combustion technique is of great interest due to its low-cost equipment, simplicity, and less processing time. In addition, homogeneity, topography, chemistry and integrity can be well controlled by adopting the auto-combustion method. In this report, the auto-combustion method has been adopted for synthesizing nanocomposites under the conditions that include doping concentration, calcination time, and temperature. Earlier literature reports the magnetic and structural properties of $\mathrm{Cu}$ doped $\mathrm{ZnO}[39,40]$. But there exist only a few studies on the dielectric, DC conductivity, and optical characteristics of such nanocomposites. Therefore, this study demonstrates the least explored domains of structural, frequency, and dopant percentage dependent dielectric properties, temperature, and dopant dependent direct current measurements and optical properties of copper doped zinc oxide nanocomposites. The results have been properly explained and discussed in the light of existing theories with respect to applications of these composite materials for possible catalytic activity.

\section{Experimental}

\subsection{Synthesis of nanocomposite materials}

Nanocomposite ZnO powder was prepared through the modest and swift auto-combustion process following the chemical reaction expressed in Eq. (1):

$$
\begin{gathered}
\mathrm{NH}_{2} \mathrm{CH}_{2} \mathrm{COOH}+\mathrm{Zn}\left(\mathrm{NO}_{3}\right)_{2} \cdot 6 \mathrm{H}_{2} \mathrm{O} \rightarrow \\
\mathrm{N}_{2}+\mathrm{CO}_{2}+\mathrm{H}_{2} \mathrm{O} \text { (vapors gas) }+\mathrm{ZnO} .
\end{gathered}
$$

Both reactants were mixed at room temperature in the desired molar ratio. At start, magnetic stirrer was used for mixing these reactants to make a homogeneous mixture. The blend was then dried by heating at around $130-150^{\circ} \mathrm{C}$. To start combustion reaction, precursor was ignited by heating again at around $220-240^{\circ} \mathrm{C}$ on hot plate. During combustion reaction, gases (non-toxic) were explosively released, following the sequence i.e., in dehydrated, in voluminous, and in loose nanocrystalline zinc oxide. This as-synthesized powder was then decomposed for three hours at $700^{\circ} \mathrm{C}$ in a furnace. Six diverse specimens were prepared by doping different contents of $\mathrm{Cu}$ and keeping molar ratio of glycine (fuel) to zinc nitrate constant at $\Psi=1.7$. Chemical reaction that occurs during the synthesis of $\mathrm{Cu}$ doped $\mathrm{ZnO}$ nanoparticles is as follows:

$$
\begin{aligned}
& \mathrm{Zn}\left(\mathrm{NO}_{3}\right)_{2} \cdot 6 \mathrm{H}_{2} \mathrm{O}+\mathrm{Cu}\left(\mathrm{NO}_{3}\right)_{2} \frac{\text { glycine }}{\left(\mathrm{CH}_{2} \mathrm{NH}_{2} \mathrm{COOH}\right)} \\
& \mathrm{Zn}_{1-x} \mathrm{Cu}_{x} \mathrm{O}+\text { gaseous products. }
\end{aligned}
$$

\subsection{Characterization methods}

X-ray diffraction (XRD) patterns were recorded using Shimadzu XD-5A powder diffraction system to identify the phase purity of these as prepared nanocomposite specimens with $\mathrm{Cu} K_{\alpha}$ radiations having wavelength $\lambda=1.5406 \AA$, whereas particle size and surface morphology of these nanocomposites were examined through scanning electron microscope (SEM, JSM 5910JEOL Japan). Flourescence spectrometer (Fluoro-Mate FS-2) was utilized in order to observe the photoluminescence (PL) emission spectrum at room temperature in the range of 400-700 $\mathrm{nm}$ at an excitation wavelength of $325 \mathrm{~nm}$. Absorption spectrum in the UV-visible region was recorded through UV-vis spectrophotometer (Hitachi U-4100) by integrating the relevant accessories in the range of 250-700 nm. Circular pellets were made for the study of dielectric properties (AC conductivity, dielectric loss, dielectric constant, etc.) at room temperature through 2-probe procedure using GW-INSTEK LCR-8101 LCR meter in the frequency range of $20 \mathrm{~Hz}$ to $1 \mathrm{MHz}$. DC conduction of these nanocomposites was examined at different temperatures by 2-probe method using DC source meter (Model 2400 Keithley) possessing huge amount of input impedance connected in series circuit configuration.

\section{Results and discussion}

\subsection{XRD analysis}

Powder X-ray diffraction patterns used to study the phase purity and structural parameters for the undoped and varying concentration of $\mathrm{Cu}$ doped $\mathrm{ZnO}$ nanoparticles are illustrated in Fig. 1. Sharp and intense 


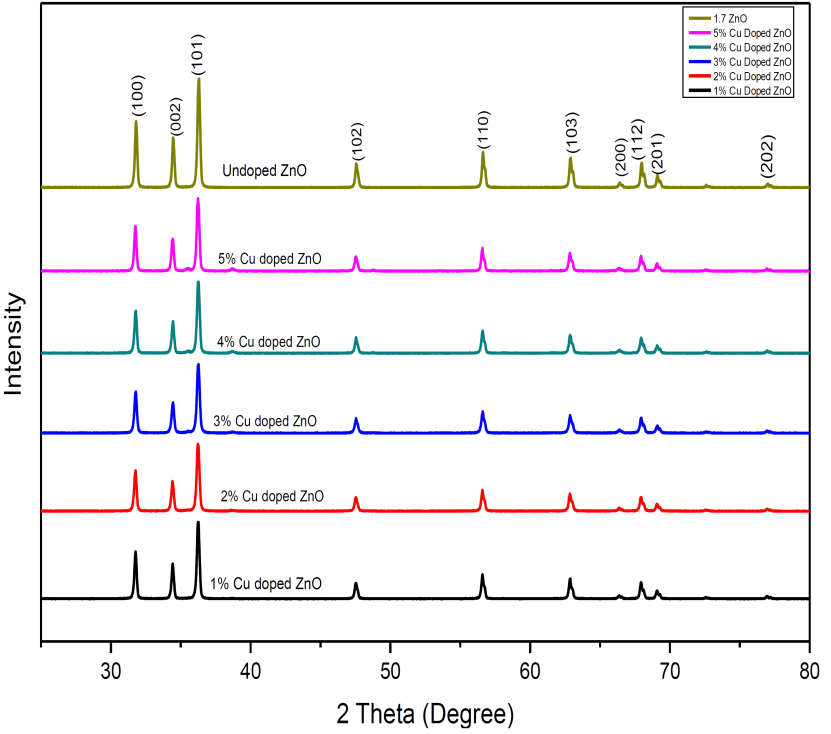

Fig. 1. XRD patterns of $\mathrm{ZnO}$ nanocomposites with different copper doping concentrations.

XRD peaks demonstrate that the deposited nanocomposites are polycrystalline in nature. Comparison of the diffraction peaks with those of the Joint Committee on Powder Diffraction Standards (JCPDS) card no. 14-1451 revealed that the nanocomposites possess hexagonal wurtzite structure. All the samples depict no traces of $\mathrm{Cu}$ related phase (oxide of copper or any zinc related copper phase, metallic copper, etc.). Instead, it reveals that $\mathrm{Cu}^{1+}$ ions have successfully replaced $\mathrm{Zn}^{2+}$ ions yielding no effect on $\mathrm{ZnO}$ crystal structure. This successful substitution is caused by the approximately equal ionic radii of $\mathrm{Zn}^{2+}(0.74 \AA)$ and $\mathrm{Cu}^{1+}(0.73 \AA)$ ions. The lattice parameters determined by considering the (102) and (101) peaks of XRD patterns are listed in Table I and were calculated by the following equation:

$$
\frac{1}{d_{(h k l)}^{2}}=\frac{4}{3}\left(\frac{h^{2}+h k+k^{2}}{a^{2}}\right)+\frac{l^{2}}{c^{2}} .
$$

Due to very small mismatch of ionic radius of $\mathrm{Cu}^{+}$ and $\mathrm{Zn}^{2+}$ ions, the lattice parameters $a$ and $c$ for all the $\mathrm{Cu}$ doped samples vary a little more than those of the undoped $\mathrm{ZnO}$. For some $\mathrm{Cu}$ doped samples, the $c / a$ ratio is slightly higher than the literature value of 1.60 (for an ideal $\mathrm{ZnO}$ structure) [41]. The almost constant $c / a$ ratio (1.60) of $\mathrm{Cu}$-ions doped nanocomposites indicates that the hexagonal wurtzite structure of pure $\mathrm{ZnO}$ has not been disturbed due to $\mathrm{Cu}$-substitution in $\mathrm{ZnO}$. A slight variation observed in the lattice parameters may be due to the existence of microstrains and lattice defects in the crystal structure. Unit cell volume and lattice parameters do not depend upon the temperature of annealing and/or on the presence of doping element but are influenced by microstrains and lattice defects in the crystal [42]. The unit cell volume of hexagonal crystal presented in Table I was calculated by the following Eq. [43]:

unit cell volume $=a^{2} c \sin 60^{\circ 3}$.

Crystallite size, lattice parameters, $c / a$ ratio, and unit cell volume for all the samples.

TABLE I

\begin{tabular}{c|c|c|c|c|c|c}
\hline \hline \multirow{2}{*}{$\begin{array}{c}\text { Serial } \\
\text { No. }\end{array}$} & Sample & \multirow{2}{*}{$\begin{array}{c}\text { Particle } \\
\text { size }[\mathrm{nm}]\end{array}$} & \multicolumn{2}{|c|}{ Lattice parameters } & \multirow{2}{*}{$c / a$ ratio } & $\begin{array}{c}\text { Unit cell volume } \\
a^{2} c \sin 60^{\circ}\left[\AA^{3}\right]\end{array}$ \\
\cline { 4 - 5 } & & 41.21 & 3.2470 & 5.1996 & 1.6013 & 47.473 \\
2 & $\mathrm{ZnO}$ & 40.42 & 3.2491 & 5.2069 & 1.6026 & 47.602 \\
3 & $\mathrm{Zn}_{0.99} \mathrm{Cu}_{0.01} \mathrm{O}$ & 39.66 & 3.2519 & 5.2099 & 1.6021 & 47.711 \\
4 & $\mathrm{Zn}_{0.98} \mathrm{Cu}_{0.02} \mathrm{O}$ & 37.86 & 3.2476 & 5.2040 & 1.6024 & 47.531 \\
5 & $\mathrm{Zn}_{0.97} \mathrm{Cu}_{0.03} \mathrm{O}$ & 36.71 & 3.2552 & 5.2040 & 1.5987 & 47.754 \\
6 & $\mathrm{Zn}_{0.96} \mathrm{Cu}_{0.04} \mathrm{O}$ & 36.39 & 3.2565 & 5.2069 & 1.5989 & 47.819
\end{tabular}

In addition, peak shift was noticed for all the $\mathrm{Cu}$ doped samples towards the small angles as compared to that of undoped $\mathrm{ZnO}$ as obvious from Fig. 2. This small peak shift is caused by the small mismatch between the ionic radii of $\mathrm{Cu}^{+}$and $\mathrm{Zn}^{2+}$ ions which looks responsible for creating the microstrains and lattice defects [43]. The average crystallite size, $t$ of all the samples was determined through Scherrer's formula (Eq. (5)) applied to the most intense diffraction peak (101) by measuring its full-width at the half maximum (FWHM), $B$, in radians [43]:

$$
t=\frac{0.9 \lambda}{B \cos \theta_{\mathrm{B}}}
$$

where $\lambda$ is X-ray wavelength equal to $1.5406 \AA$ and $\theta_{\mathrm{B}}$ is Bragg's angle in radians. For all the $\mathrm{Cu}$ doped $\mathrm{ZnO}$ samples, the average crystallite size has been noted to reduce almost linearly with rising $\mathrm{Cu}$ content in the $\mathrm{ZnO}$ nanoparticles as compared to that observed for pure $\mathrm{ZnO}$ as depicted by Fig. 3 and shown in Table I. An approximate relation between these parameters (the average crystallite size and $\mathrm{Cu}$ concentration) is depicted in the following equation:

$$
t=41.3533-1.0580 c \%,
$$

where $c[\%]$ represents the $\%$ concentration of $\mathrm{Cu}$ doping. A possible cause of reduction in crystallite size is an increase in the rate of nucleation with increasing the 


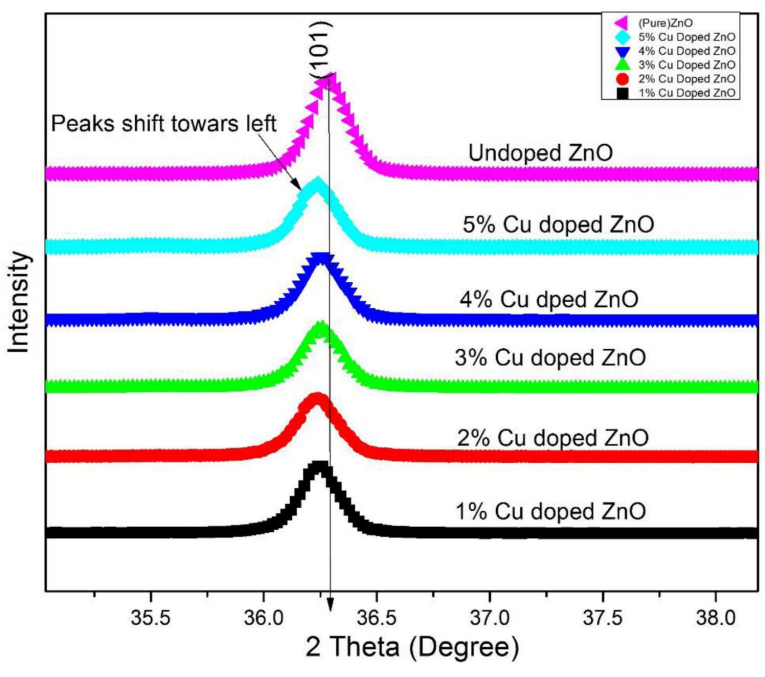

Fig. 2. Peak shift to small angles for $\mathrm{Cu}$ doped samples as compared to the undoped $\mathrm{ZnO}$.

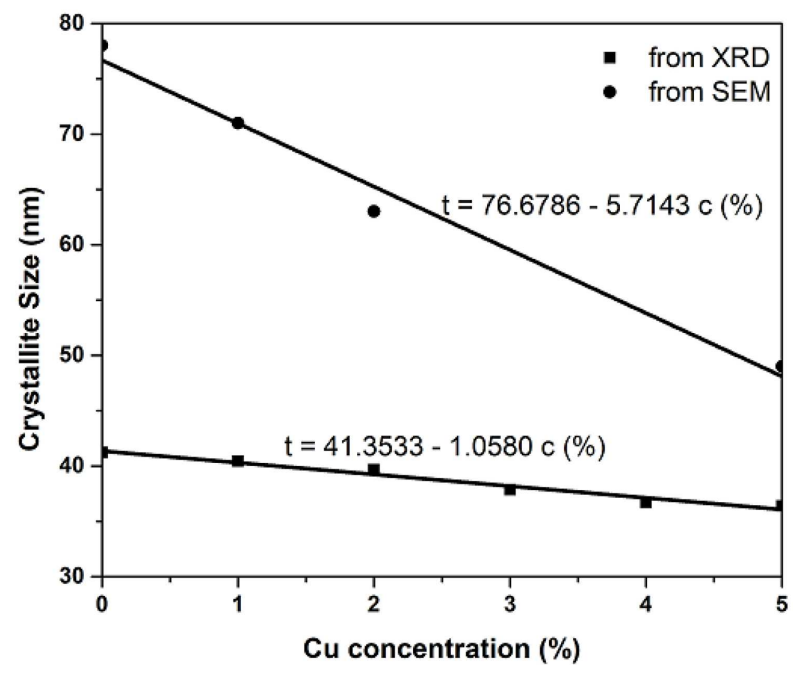

Fig. 3. XRD crystallite size as a function of $\mathrm{Cu}$ doping concentration.

number of $\mathrm{Cu}$ atoms (ions) in the lattice, which may act as seed crystals to assist and enhance the process of nucleation as compared to rate of growth of these crystallites. In addition, a slight difference in ionic radii of $\mathrm{Zn}^{2+}$ and $\mathrm{Cu}^{+}$may also be a cause of decrease in the crystallite size. In spite of this fact, copper doping in $\mathrm{ZnO}$ hinders the motion of grain boundaries and obstructs the growth of crystallites. The Zener pinning theory explains this fact, illustrating the motion of grain boundaries across the grain's edges [44]. According to this theory, an impending force is exerted by the crystallite's edges on the moving boundaries and these moving boundaries might get stuck upon replacement of $\mathrm{Zn}$ atoms by $\mathrm{Cu}$ ions and possibly $\mathrm{Zn}$ interstitials. As a result, crystallite development is prohibited as the impeding power is stronger than the main driving force for the grain development [45]. There might be some charge imbalance and crystal defects around the dopants due to doping of $\mathrm{Cu}$ in $\mathrm{ZnO}$.

\subsection{Scanning electron microscopy}

SEM is usually practised for analyzing topography of the crystallites, as it reveals noteworthy facts regarding the size, the evolution process, and the shape of crystallites. SEM micrographs depicting morphology of the surfaces of all the nanocomposites are shown in Fig. $4 \mathrm{a}-\mathrm{d}$. It is evident from all of these SEM images that the average crystallites size is of the order of nanometer. SEM images also demonstrate the almost spherical or slightly elongated morphology of the crystallites in all the nanocomposite materials. Moreover, the crystallites are homogeneous and uniformly distributed throughout the lattice. Shape and size of the particles are largely developed by the presence of defects. Average crystallite size of undoped $\mathrm{ZnO}$ nanocomposite was determined through SEM images to be $78 \mathrm{~nm}$ which decreased to $49 \mathrm{~nm}$ for $\mathrm{Cu}$ doped composites as demonstrated by Fig. 3 along with crystallite size calculated through XRD. In both cases the trend is similar, but the magnitudes are larger, and the rate of decrease is relatively faster for SEM measurements as compared to those for XRD as obvious from Fig. 3. Observed morphology of particles is expected to be mostly developed by the release of large amount of gases during combustion reaction, which made particles surfaces spongy-like. This sponginess of particles causes a reduction in the density. But with the addition of $\mathrm{Cu}$ dopant to the composites, surfaces became less porous due to the emission of relatively lesser amounts of gases during combustion. Consequently, with the disappearance of surface pores/holes, porosity of the samples is decreased and hence their density is increased. Additionally, with rising dopant concentration, the tendency of agglomeration among smaller particles was noted.
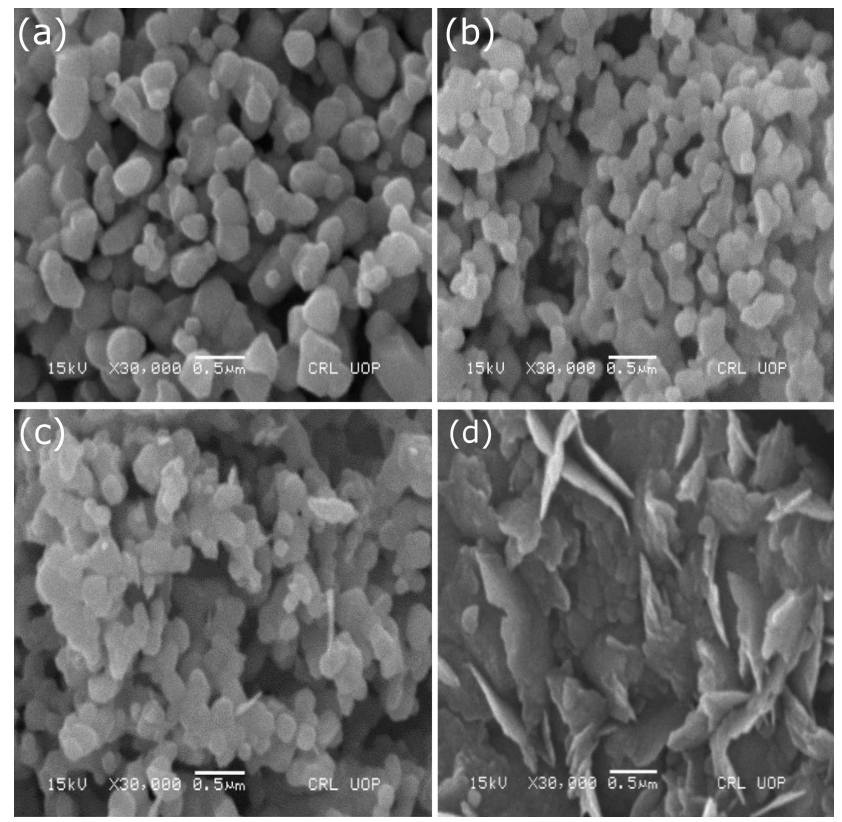

Fig. 4. SEM images of undoped (a), 1\% (b), 2\% (c), and $5 \%$ (d) $\mathrm{Cu}$ doped $\mathrm{ZnO}$ nanoparticles. 


\subsection{Dielectric characteristics}

\subsubsection{Dielectric constant $\varepsilon_{r}$}

Dielectric constant of a substance in general depends upon the applied frequency of AC field, the crystal structure, and temperature of measurement. Three dielectric parameters, including $\mathrm{AC}$ conduction, dielectric loss, and dielectric constant were measured at room temperature as a function of frequency in the range from $20 \mathrm{~Hz}$ to $1 \mathrm{MHz}$ for undoped and copper doped $\mathrm{ZnO}$ nanocomposites. Relation used to compute dielectric constant is given by

$$
\varepsilon_{r}=\frac{C L}{A \varepsilon_{0}},
$$

where capacitance $C$ of the dielectric material is measured in farad $(\mathrm{F}), L$ indicates pellet thickness, crosssectional area of the pellet is $A$ and $\varepsilon_{0}$ shows permittivity of free space $\left(8.85 \times 10^{-12} \mathrm{~F} / \mathrm{m}\right)$. The variations of dielectric constant $\varepsilon_{r}$ versus AC field frequency is revealed in Fig. 5.

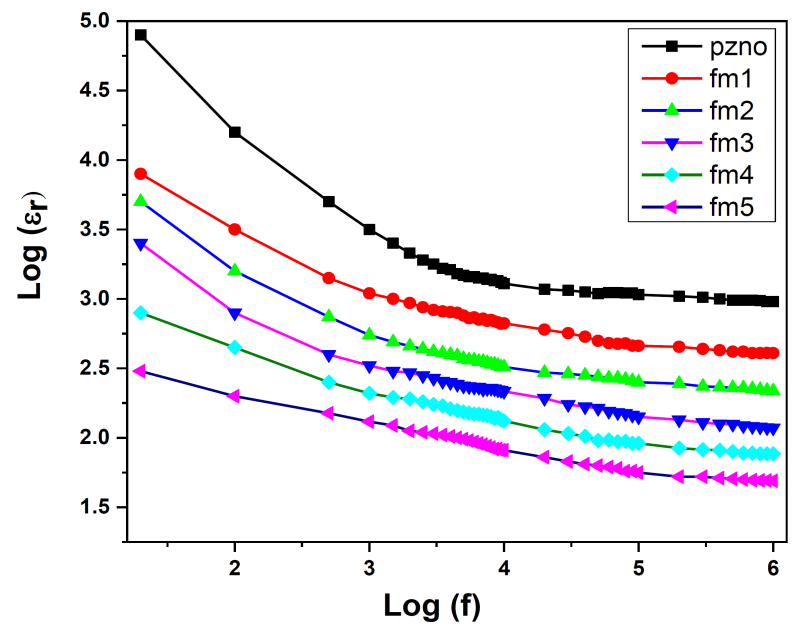

Fig. 5. Variations of $\varepsilon_{r}$ vs. frequency for undoped and $\mathrm{Cu}$ doped $\mathrm{ZnO}$ nanocomposites.

Figure 5 illustrates that $\varepsilon_{r}$ is high at lower frequencies, but it declines gradually and turns into nearly persistent value in the high frequency range. Such $\varepsilon_{r}$ declination might be associated with the formation of nanocrystallites surrounded by insulating grain boundaries. When $\mathrm{AC}$ field is applied, material becomes polarized, which lowers resultant field in the material. Consequently, with rise in frequency, $\varepsilon_{r}$ might decline. Already existing theories such as the Koops [46] theory and polarization philosophy of the Maxwell-Wagner [47, 48] can explain such type of dielectric constant behavior. As suggested by these theories, a dielectric material is comprised of conductive grains isolated by conductive grain boundaries which are poorly resistive. The size of grain boundaries is reduced with an increase in the crystallite size. Since crystallites are nanosized particles so they develop more grain boundaries. At high frequencies, grains become more effective while at low frequencies grain boundaries predominate. During sintering process, crystallite and hence grain boundaries are formed because of oxidation or reduction of particles surfaces [49]. The relatively sharp behavior of $\varepsilon_{r}$ at low frequencies and almost constant behavior at high frequencies lead to dielectric relaxation. Polarization of a material due to applied AC bias causes such dielectric relaxation. Charge carriers which are gathered at grain boundaries can migrate the grains by the application of AC field. Therefore, on the application of biasing field, such charge carriers easily migrate the grains which are accumulated at the grain boundaries. Consequently, large $\varepsilon_{r}$ and polarization can be produced. The large value of $\varepsilon_{r}$ at low frequencies is caused by low conduction through grain boundaries. In addition, inhomogeneous dielectric structure inducing interfacial or space charge polarization can also be responsible for this high value of $\varepsilon_{r}$. Furthermore, porosity is also among inhomogeneities of the materials. An upsurge in the frequency of applied field causes a decrease in polarization, which afterwards approaches a persistent rate. Such gradual fall of dielectric constant might be related with the hopping mechanism of metallic ions $\left(\mathrm{Zn}^{2+}\right.$, $\left.\mathrm{Cu}^{+}\right)$. At lower frequencies, large proportion of $\varepsilon_{r}$ might be caused by the presence of defects such as oxygen vacancies, grain boundaries, etc., while reduction in $\varepsilon_{r}$ by a rise in frequency of the $\mathrm{AC}$ biasing field could be associated with lagging of polarizability behind higher frequencies [50].

\subsubsection{Dielectric loss $(\tan \delta)$}

Dielectric loss $(\tan \delta)$ represents the dissipated energy in dielectric systems caused by resonance of domain walls. Imperfections and dopants (impurities) play effective role in the lagging of polarization on the application of $\mathrm{AC}$ field, which leads to dielectric loss. Deterioration of $\varepsilon_{r}$ and $\tan (\delta)$ can also be attributed to decrease in density caused by enhancement in porosity [51]. The low values of loss $\tan (\delta)$ at large $\mathrm{AC}$ frequencies could be linked with variations in field alignment caused by magnetization and impeded movement of domain walls [51].

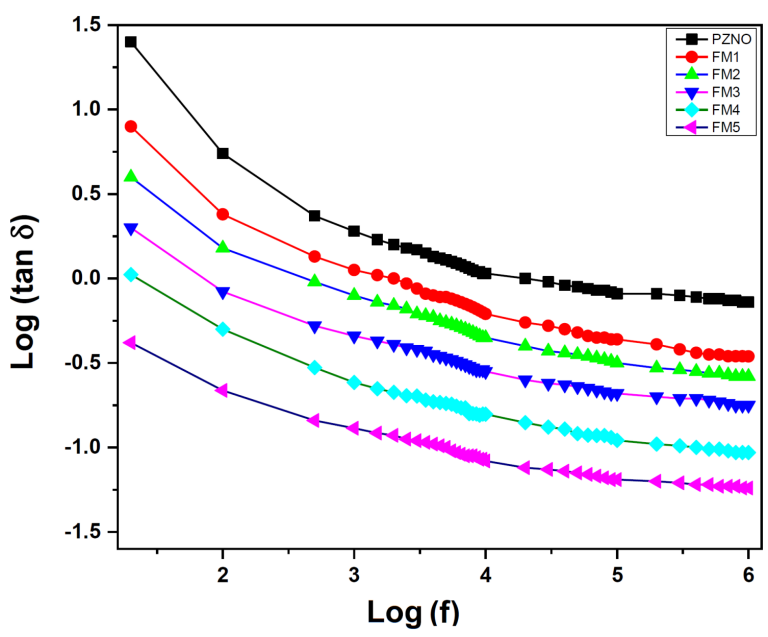

Fig. 6. Variations of dielectric loss versus frequency of undoped and $\mathrm{Cu}$ doped $\mathrm{ZnO}$. 
The observed variations in $\tan (\delta)$ against frequencies of AC field at room temperature is displayed in Fig. 6. It is notable that dielectric loss reveals analogous graphical behavior as noticed for dielectric constant. It is known that the loss $\tan (\delta)$ becomes high due to polarization of space charges in the low frequency region [52]. As molecules are reoriented in polar dielectrics, some energy is dissipated by stresses because of internal friction. In addition, the diffusion of bipolar molecules from one site to the other utilizes some of the electrical energy that plays a role in the reduction of dielectric energy and hence leads to the dielectric loss. Absorption currents create dielectric loss due to the unequal distribution of defects and space charge in different layers. Polarization of space charges reduces $\tan (\delta)$ [53]. Consequently, devices which operate at high frequencies are based on such materials whose dielectric loss reduces upon rising dopant quantity.

\subsubsection{AC electrical conductivity $\left(\sigma_{A C}\right)$}

Following relation can be applied to calculate AC electrical conductivity,

$$
\sigma_{\mathrm{AC}}=2 \pi f \varepsilon_{0} \varepsilon_{r} \tan \delta,
$$

which shows that $\mathrm{AC}$ conductivity is proportional to applied AC frequency and loss $\tan (\delta)$ as demonstrated in Fig. 7. It is noted that variations in $\sigma_{\mathrm{AC}}$ are slow and gradual at lower frequencies but relatively swift at higher ones. The Maxwell-Wagner interfacial model suggests the key role of grain boundaries as potential barriers so charge carriers inside grains behave like charges in potential well [54]. That is why such charge carriers can move easily within grains but due to resistive interfaces between grains, these charge carriers cannot migrate between grains.

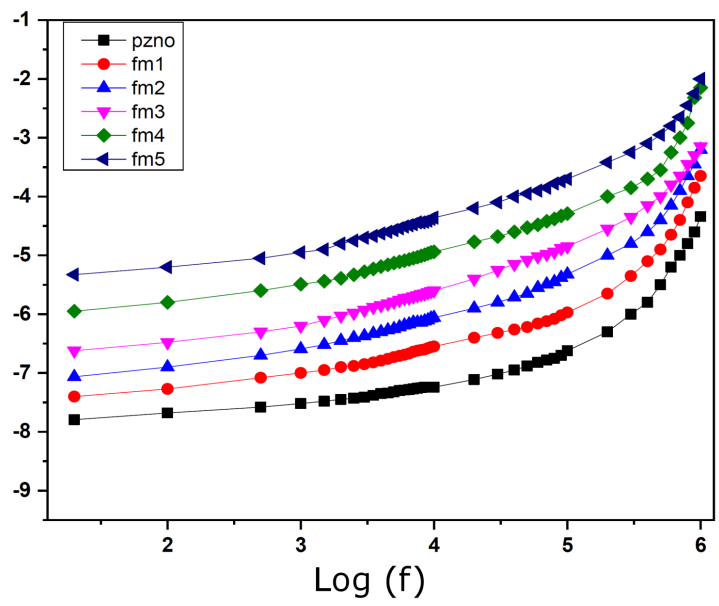

Fig. 7. Variations of AC conductivity versus frequency of undoped and $\mathrm{Cu}$ doped $\mathrm{ZnO}$.

At low frequencies, a gradual but weak conduction takes place because charge carriers are weakly drifting among grains. While rise in frequency can upsurge/enhance the tunneling of charge carriers leading to improvement in the $\mathrm{AC}$ conduction. Beyond certain value of increasing AC frequency, charge carriers can acquire enough amount of energy to surmount the potential barrier causing to speed up the charge conduction. Figure 7 also depicts that by increasing the dopant $(\mathrm{Cu})$ quantity $\mathrm{AC}$ conduction shows improvement very much as compared to that of intrinsic $\mathrm{ZnO}$. This increase in conduction may be associated with increase in charge carriers by increasing dopant percentage as $\mathrm{Cu}$ is a good conductor having a lot of free electrons [55]. Increasing dopant concentration causes to increase the number of charge carriers which can easily overcome the potential barrier or charge carrier's blocking defects. Therefore, hopping process improves by rise in charge carriers predominating blocking defects leading to increase in conductivity [56]. Additionally, hopping process can also be improved by increase of frequency of applied AC field, which can assist in decrease of the resistivity and hence increase of the conductivity [57].

\subsection{DC electrical conductivity $\left(\sigma_{D C}\right)$}

Intrinsic and extrinsic copper doped $\mathrm{ZnO}$ composites have also been investigated to assess the DC conduction at room temperature $\left(27^{\circ} \mathrm{C}\right)$ as well as with rising temperatures $\left(50,75,100\right.$, and $\left.125^{\circ} \mathrm{C}\right)$. Computation of DC conductivity was carried out through current-voltage $(I-V)$ data using the following relation:

$$
\sigma_{\mathrm{DC}}=(L / A) R,
$$

where resistance, area of the effective surface, and thickness of the pellet is represented by $R(=I / V), A$, and $L$, respectively. Figure 8 shows DC conductivity of undoped and $\mathrm{Cu}$ doped composites, which demonstrates an increase in DC conductivity by increasing temperature displaying behavior analogous to that of semiconductors for all the undoped and $\mathrm{Cu}$ doped nanocomposites. In addition, it is noted that $\mathrm{DC}$ conductivity also raises with a rise in the concentration of copper in the $\mathrm{ZnO}$ nanocomposites. Such increase in DC conductivity of $\mathrm{ZnO}$ composites could be attributed to the highly conductive nature of copper because of having a lot of free electrons and being the noble metal.

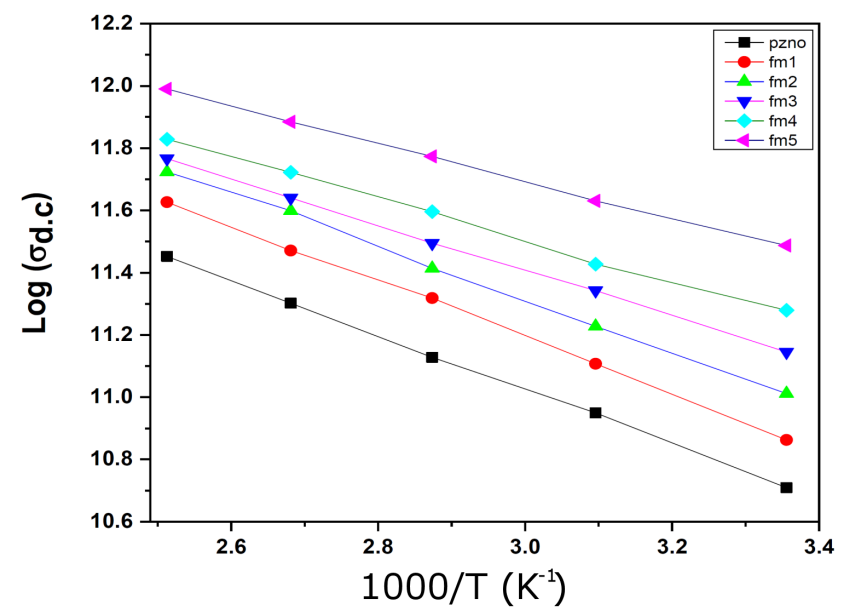

Fig. 8. Variations of logarithm of DC electrical conductivity $\log \left(\sigma_{\mathrm{DC}}\right)$ versus $1000 / T$ of intrinsic and $\mathrm{Cu}$ doped $\mathrm{ZnO}$. 
DC conductivity increase with rising temperature causes to multiply the natural defects such as oxygen vacancies and interstitial zinc atoms [58]. Hopping of charge carriers (electrons or holes) occurs among localized states during conduction. During hopping of electrons, perturbation takes place around molecules following the changes in structure as well as atomic polarization which happens as a result of hole or electron trapping. Such hopped electrons or holes try to affiliate with natural defects [59]. Moreover, increase in conductivity by increasing copper content and decreasing $\mathrm{Zn}$ ions in the $\mathrm{Cu}$-doped $\mathrm{ZnO}$ could be attributed to non-stoichiometric nature of the material and to oxygen deficit produced by copper. Since $\mathrm{Cu}$ in $\mathrm{ZnO}$ is expected to transform into non-stoichiometric semiconducting oxide $\left(\mathrm{Cu}_{x} \mathrm{O}_{y}\right)$.

\subsection{Optical properties}

\subsubsection{UV-visible spectrophotometry}

As it is known that $\mathrm{ZnO}$ is a direct band gap material, so to estimate optical band gap energy of the pure and copper doped zinc oxide nanocomposites $\left(\mathrm{Zn}_{1-x} \mathrm{Cu}_{x} \mathrm{O}\right)$ having different compositions with $x=0.01$ to 0.06 , absorbance spectra have been recorded at room temperature in the spectral region of $250-700 \mathrm{~nm}$. The optical band gap energy $E_{g}$ values of pure and doped zinc oxide have been estimated from these plots of absorbance versus wavelength of all these nanocomposites as shown in Fig. 9. The junction of two rectilinear regions have been utilized to deduce $E_{g}$ values which are presented in Table II. Following relation was used to compute the energy band gap:

$$
E=h c / \lambda \text {, }
$$

where $h$ - Planck's constant $=6.63 \times 10^{-34} \mathrm{~J} \mathrm{~s}, c$ speed of light $=3 \times 10^{8} \mathrm{~m} / \mathrm{s}, h c=1241.5 \mathrm{eV} \mathrm{nm}$, and $\lambda$ — incident wavelength (in $\mathrm{nm}$ ). Figure 9 illustrates that the absorption spectra of intrinsic and copper doped $\mathrm{ZnO}$ nanocomposites are not similar and the band edges have been shifted to longer wavelengths depicting red shift on doping copper into $\mathrm{ZnO}$ nanocomposites. The optical

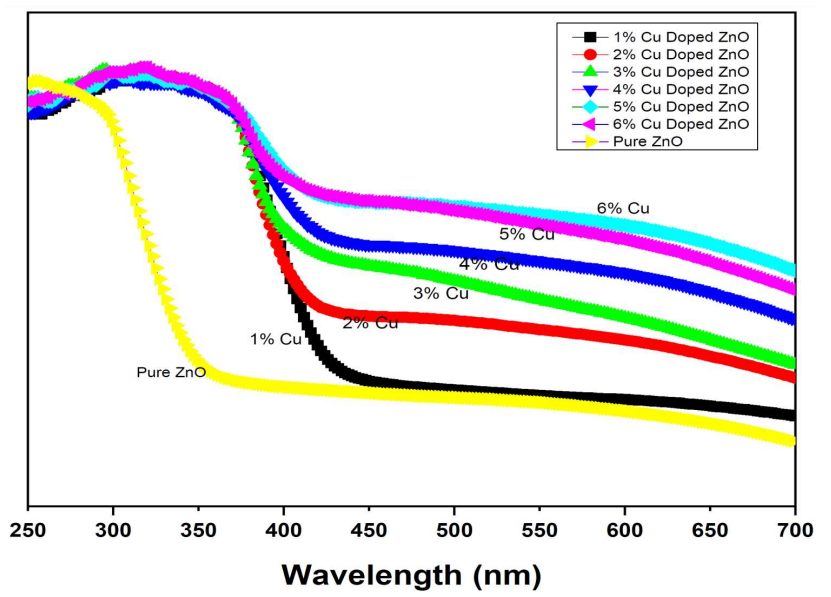

Fig. 9. Diffuse reflectance spectroscopy (DRS) of undoped and $\mathrm{Cu}$ doped $\mathrm{ZnO}$ nanocomposites.
TABLE II

Band gap versus wavelength determined from DRS.

\begin{tabular}{c|l|c|c}
\hline \hline $\begin{array}{c}\text { Serial } \\
\text { No. }\end{array}$ & Sample & $\begin{array}{c}\text { Wavelength } \\
\lambda[\mathrm{nm}]\end{array}$ & $\begin{array}{c}E_{g}=h c / \lambda \\
{[\mathrm{eV}]}\end{array}$ \\
\hline 1 & $\mathrm{ZnO}$ & 366.0 & 3.39 \\
2 & $\mathrm{Zn}_{0.99} \mathrm{Cu}_{0.01} \mathrm{O}$ & 442.0 & 2.81 \\
3 & $\mathrm{Zn}_{0.98} \mathrm{Cu}_{0.02} \mathrm{O}$ & 445.9 & 2.78 \\
4 & $\mathrm{Zn}_{0.97} \mathrm{Cu}_{0.03} \mathrm{O}$ & 457.0 & 2.72 \\
5 & $\mathrm{Zn}_{0.96} \mathrm{Cu}_{0.04} \mathrm{O}$ & 466.5 & 2.66 \\
6 & $\mathrm{Zn}_{0.95} \mathrm{Cu}_{0.05} \mathrm{O}$ & 494.0 & 2.51 \\
7 & $\mathrm{Zn}_{0.94} \mathrm{Cu}_{0.06} \mathrm{O}$ & 503.5 & 2.47
\end{tabular}

band gap estimated for pure zinc oxide is $3.39 \mathrm{eV}$, which is slightly higher than its value for bulk zinc oxide $(3.37 \mathrm{eV})$. This $E_{g}$ value suddenly drops to $2.81 \mathrm{eV}$ by doping $\mathrm{Cu}$ into $\mathrm{ZnO}$. The absorbance spectra of $\mathrm{Cu}$ doped zinc oxide $\left(\mathrm{Zn}_{1-x} \mathrm{Cu}_{x} \mathrm{O}\right)$ further shows that, as the concentration of copper increases $(x=0.01$ to 0.06$)$, band gap values decrease as obvious from Table II. These absorbance spectra reveal that $\mathrm{Cu}$ doping has led to some structural disorder in the zinc oxide lattice. Relatively sharp characteristic edge at about $366 \mathrm{~nm}$ indicates impurity suppressed good crystallinity of $\mathrm{ZnO}$. Since absorption edge has shifted towards longer wavelengths, this indicates association of the surface oxides of $\mathrm{Zn}$ and $\mathrm{Cu}$ [60]. Moreover, such red shift might be due to increase in adsorption by enhancing copper content. By increasing copper content in the $\mathrm{ZnO}$ nanocomposite, shift in absorption edge to higher wavelengths further increases. In addition, increment in absorbance in the visible range is also noticed with increase of doping content. The photo-induced transition between valence and conduction bands and the impurity levels have been suggested to effectively improve light absorption in the visible light region [61, 62]. A rise in absorbance by enhancing copper content may be associated with a reduction in the size of nanocrystallites, and an enhancement in sponginess leads to decrease in the density, which causes narrowing of the band gap energy [63].

\subsubsection{Photoluminescence spectroscopy (PLS)}

Photoluminescence emission spectra of undoped and copper doped $\mathrm{ZnO}$ nanocomposites recorded at room temperature are shown in Fig. 10. The PL emission spectra shown in Fig. 10 demonstrate two broad peaks in the region between 375 and $475 \mathrm{~nm}$ for all the undoped and copper doped $\mathrm{ZnO}$ nanocomposites. A broad photoluminescence emission spectrum has already been observed from localized surface states of $\mathrm{ZnO}$ in the range of $340 \mathrm{~nm}$ to $550 \mathrm{~nm}$, which was suggested to be formed due to recombination of photo-induced charge carriers [64]. The broad peaks centered at $398 \mathrm{~nm}$ and $442 \mathrm{~nm}$ appeared in undoped $\mathrm{ZnO}$ composites. The $\mathrm{PL}$ emission peak observed at $398 \mathrm{~nm}$ called UV emission might be attributed to the free excitation discharge at about $3.39 \mathrm{eV}$ related to $\mathrm{ZnO}$ band gap, $E_{g}$. This broad peak appears to be shifting towards higher wavelengths upon $\mathrm{Cu}$ doping into $\mathrm{ZnO}$ lattice, since more defects are produced as $\mathrm{Cu}^{+}$ 


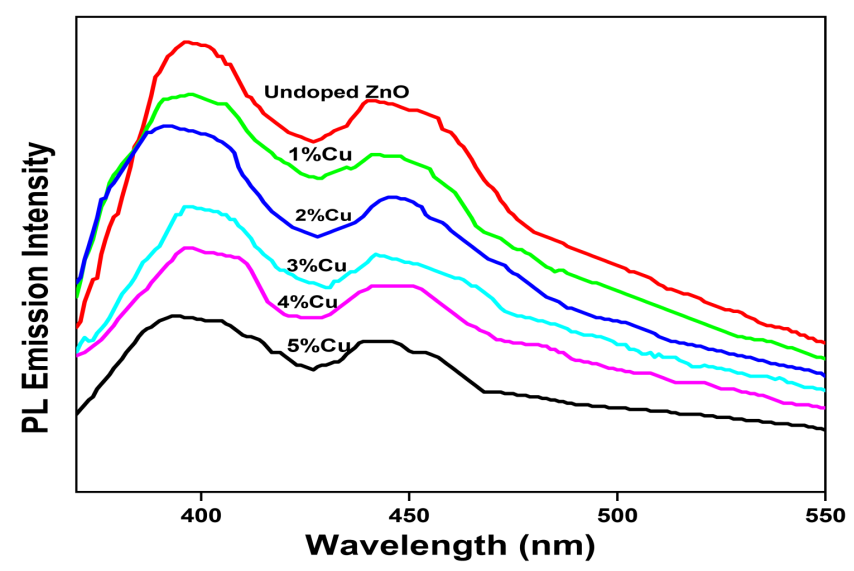

Fig. 10. PL emission intensity vs. wavelength of undoped and $\mathrm{Cu}$ doped $\mathrm{ZnO}$ nanocomposites.

substitutes $\mathrm{Zn}^{2+}$ into the $\mathrm{ZnO}$ sublattice, consequently narrowing the $E_{g}$ [65-67]. Being a decent electron acceptor, copper acts as electron trapper for the electrons of $\mathrm{ZnO}$ excited from valence to conduction bands and so excellently reduces the recombination of electron-hole pairs leading to enhancement in the charge carrier parting [28]. Intensity of PL emission declines by increasing copper content as displayed by Fig. 10. Such a decrease in PL emission intensity is found to be in accordance with the earlier literature reports [68]. It is known that recombination of the photogenerated electrons and holes during de-excitation produces PL emission spectrum. Small recombination percentage is the indication of less brightness by electrons and holes, whereas high emission intensity means high recombination rate. As PL emission intensity decreases on increasing copper content in the $\mathrm{ZnO}$ lattice, it implies that the recombination rate of photogenerated carrier's decreases effectively. Pure ZnO has the highest PL intensity while $5 \%$ copper doped $\mathrm{ZnO}$ gives the lowest emission intensity. Such a decrease in PL emission intensity by copper doping in $\mathrm{ZnO}$ nanocomposites is important for better photocatalytic activity.

\section{Conclusions}

$\mathrm{Cu}$ doped $\mathrm{ZnO}$ nanocomposite fabricated by autocombustion technique has been investigated for structural, dielectric, direct current, and photoluminescence properties. XRD data suggests that $\mathrm{ZnO}$ lattice structure does not change upon $\mathrm{Cu}$ doping. The crystallite size measured by XRD appears to decrease upon $\mathrm{Cu}$ doping, it is also verified by SEM measurements. SEM images also suggest the spherical morphology of particles with sponge-like nature. Dielectric measurements including dielectric constant, dielectric loss $\tan (\delta)$, and AC conductivity were made on the basis of the Maxwell-Wagner theory as functions of $\mathrm{Cu}$ concentration as well as $\mathrm{AC}$ frequency. Dielectric constant and dielectric loss $\tan (\delta)$ both decrease on enhancing $\mathrm{Cu}$ concentration in the composites and also with rising frequency of the $\mathrm{AC}$ source, while AC conduction displays opposite trend on increasing copper concentration as well as AC source frequency.
Similarly, DC electrical conductivity also shows improvement by rise in $\mathrm{Cu}$ quantity and temperature. Optical properties of $\mathrm{ZnO}$ can be tuned by $\mathrm{Cu}$ doping and reveal reduction in energy band gap $E_{g}$. The observed decrease in photoluminescence emission intensity could be associated with reduction in the percent recombination of photo-induced electron-hole pairs as a result of $\mathrm{Cu}$ doping. The improved electrical and optical properties of $\mathrm{ZnO}$ nanocomposites upon $\mathrm{Cu}$ doping make these composites suitable for different optoelectronics devices, light emitting diodes, varistors, and effectively increase their photocatalytic efficiency.

\section{Acknowledgments}

Mian Faisal Manzoor thankfully acknowledges supervision of Professor Dr. Ejaz Ahmad and financial support from Higher Education Commission, Pakistan for this endeavor.

\section{References}

[1] S.A. Ansari, M.M. Khan, S. Kalathil, A. Nisar, J. Lee, M.H. Cho, Nanoscale 5, 9238 (2013).

[2] I. Khan, S. Khan, R. Nongjai, H. Ahmed, W. Khan, Opt. Mater. 35, 1189 (2013).

[3] X. Jin, J. Strueben, L. Heepe, A. Kovalev, Y.K. Mishra, R. Adelung, S.N. Gorb, A. Staubitz, Adv. Mater. 24, 5676 (2012).

[4] J. Lee, J. Chae, K. Nahm, M. Kang, J. Industr. Eng. Chem. 15, 645 (2009).

[5] C.-C. Lin, Y.-J. Chiang, J. Industr. Eng. Chem. 18, 1233 (2012).

[6] D.R. Zhang, H.L. Liu, S.Y. Han, W.X. Piao, J. Industr. Eng. Chem. 19, 1838 (2013).

[7] I.-T. Kim, M. Choi, H.-K. Lee, J. Shim, J. Industr. Eng. Chem. 19, 813 (2013).

[8] M. Wang, Y. Gao, L. Dai, C. Cao, X. Guo, J. Solid State Chem. 189, 49 (2012).

[9] Z. Liu, C. Liu, J. Ya, E. Lei, Renew. Energy 36, 1177 (2011).

[10] F. Meng, J. Yin, Y.-Q. Duan, Z.-H. Yuan, L.-J. Bie, Sens. Actuat. B Chem. 156, 703 (2011).

[11] H. Kim, A. Pique, J. Horwitz, H. Murata, Z. Kafafi, C. Gilmore, D. Chrisey, Thin Solid Films 377, 798 (2000).

[12] K. Milenova, I. Stambolova, V. Blaskov, A. Eliyas, S. Vassilev, M. Shipochka, J. Chem. Technol. Metall. 48, 259 (2013).

[13] H. Zhang, B. Chen, H. Jiang, C. Wang, H. Wang, X. Wang, Biomaterials 32, 1906 (2011).

[14] S. Navarro, J. Fenoll, N. Vela, E. Ruiz, G. Navarro, J. Hazard. Mater. 172, 1303 (2009).

[15] L.-C. Chen, C.-M. Huang, M.-C. Hsiao, F.-R. Tsai, Chem. Eng. J. 165, 482 (2010).

[16] F.-H. Chu, C.-W. Huang, C.-L. Hsin, C.-W. Wang, S.-Y. Yu, P.-H. Yeh, W.-W. Wu, Nanoscale 4, 1471 (2012).

[17] C.-C. Chen, H.-J. Fan, J.-L. Jan, J. Phys. Chem. C 112, 11962 (2008). 
[18] I. Ahmad, E. Ahmed, M. Ullah, A.M. Rana M.F. Manzoor, M.A. Rasheed, A.S. Malick, N.R. Khalid, M. Ahmad, U. Mehtab, J. Ovon Res. 14, 415 (2018).

[19] S. Bernik, N. Daneu, A. Rečnik, J. Europ. Ceram. Soc. 24, 3703 (2004).

[20] D.P. Norton, Y. Heo, M. Ivill, K. Ip, S. Pearton, M.F. Chisholm, T. Steiner, Mater. Today 7, 34 (2004).

[21] T. Watari, R.C. Bradt, J. Ceram. Soc. Jpn. 101, 1085 (1993).

[22] S. Bernik, P. Zupančič, D. Kolar, J. Europ. Ceram. Soc. 19, 709 (1999).

[23] I.N. Reddy, Ch.V. Reddy, M. Sreedhar, J. Shim, M. Cho, D. Kim, Mater. Sci. Eng. B 240, 33 (2019).

[24] R. Raguvaran, A. Manuja, B.K. Manuja, Immunome Res. 11, 1 (2015)

[25] X. He, H. Qian, Q. Zhi, M. Zhang, J. Luo, R. He, Q. Zeng, Appl. Surf. Sci. 283, 571 (2013).

[26] B. Yuan, Y. Wang, H. Bian, T. Shen, Y. Wu, Z. Chen, Appl. Surf. Sci. 280, 523 (2013).

[27] F. Liu, M.Y. Guo, Y.H. Leung, A.B. Djurišić, A.M.C. Ng, W.K. Chan, Appl. Surf. Sci. 283, 914 (2013)

[28] M. Ahmad, Z. Hong, E. Ahmed, N. Khalid, A. Elhissi, W. Ahmad, Ceram. Int. 39, 3007 (2013).

[29] M. Ahmad, E. Ahmed, Y. Zhang, N. Khalid, J. Xu, M. Ullah, Z. Hong, Curr. Appl. Phys. 13, 697 (2013).

[30] N. Khalid, Z. Hong, E. Ahmed, Y. Zhang, H. Chan, M. Ahmad, Appl. Surf. Sci. 258, 5827 (2012).

[31] M. Ahmad, E. Ahmed, Z. Hong, J. Xu, N. Khalid, A. Elhissi, W. Ahmed, Appl. Surf. Sci. 274, 273 (2013).

[32] N. Khalid, E. Ahmed, Z. Hong, Y. Zhang, M. Ahmad, Curr. Appl. Phys. 12, 1485 (2012).

[33] M. Ahmad, E. Ahmed, Z. Hong, N. Khalid, W. Ahmed, A. Elhissi, J. Alloys Comp. 577, 717 (2013).

[34] S. Muthukumaran, R. Gopalakrishnan, Opt. Mater. 34, 1946 (2012).

[35] M. Salavati-Niasari, F. Davar, A. Khansari, J. Alloys Comp. 509, 61 (2011).

[36] R. Savu, R. Parra, E. Joanni, B. Jančar, S.A. Eliziário, R. de Camargo, P.R. Bueno, J.A. Varela, E. Longo, M.A. Zaghete, J. Cryst. Growth 311, 4102 (2009).

[37] R. Chauhan, A. Kumar, R.P. Chaudhary, J. Chem. Pharmaceut. Res. 2, 178 (2010).

[38] R. Elilarassi, G. Chandrasekaran, Optoelectron. Lett. 6, 6 (2010).

[39] Q. Xu, S. Zhou, H. Schmidt, J. Alloys Comp. 487, 665 (2009).

[40] N. Thaweesaeng, S. Supankit, W. Techidheera, W. Pecharapa, Energy Proced. 34, 682 (2013).

[41] J. Schneider, G. Li, A. Franke, B. Zhou, J. Magn. Magn. Mater. 424, 26 (2017).
[42] S. Thakur, N. Sharma, A. Varkia, J. Kumar, Adv. Appl. Sci. Res. 5, 18 (2014).

[43] B.D. Cullity, Elements of X-Ray Diffraction, AddisonWesley, Reading (MA) 1978, p. 102

[44] F. Humphreys, M. Ardakani, Acta Mater. 44, 2717 (1996).

[45] X. Wang, R. Zheng, Z. Liu, H.-P. Ho, J. Xu, S.P. Ringer, Nanotechnology 19, 455702 (2008).

[46] C. Koops, Phys. Rev. 83, 121 (1951).

[47] M. Levin, M. Miller, Usp. Fiz. Nauk 135, 425 (1981).

[48] K.W. Wagner, Ann. Phys. 345, 817 (1913).

[49] M. El Hiti, J. Magn. Magn. Mater. 192, 305 (1999).

[50] S.A. Ansari, A. Nisar, B. Fatma, W. Khan, A. Naqvi, Mater. Sci. Eng. B 177, 428 (2012).

[51] R. Mangalaraja, P. Manohar, F. Gnanam, M. Awano, J. Mater. Sci. 39, 2037 (2004).

[52] S. Kamba, V. Bovtun, J. Petzelt, I. Rychetsky, R. Mizaras, A. Brilingas, J. Banys, J. Grigas, M. Kosec, J. Phys. Condens. Matter 12, 497 (2000)

[53] D.M. Prabaharan, K. Sadaiyandi, M. Mahendran, S. Sagadevan, Mater. Res. 19, 478 (2016).

[54] M.S. Samuel, J. Koshy, A. Chandran, K. George, Physica B Condens. Matter 406, 3023 (2011).

[55] R. Zamiri, B. Singh, M.S. Belsley, J. Ferreira, Ceram. Int. 40, 6031 (2014).

[56] A. Azam, A.S. Ahmed, M.S. Ansari, A.H. Naqvi, J. Alloys Comp. 506, 237 (2010).

[57] K.M. Batoo, S. Kumar, C.G. Lee, Curr. Appl. Phys. 9, 1072 (2009).

[58] A. Sawalha, M. Abu-Abdeen, A. Sedky, Physica B Condens. Matter 404, 1316 (2009).

[59] M. Hossain, R. Islam, K. Khan, Chalcogen. Lett. 7 , 21 (2010)

[60] M. Fu, Y. Li, P. Lu, J. Liu, F. Dong, Appl. Surf. Sci. 258, 1587 (2011).

[61] P. Jongnavakit, P. Amornpitoksuk, S. Suwanboon, N. Ndiege, Appl. Surf. Sci. 258, 8192 (2012).

[62] W.-J. Qin, J. Sun, J. Yang, X.-W. Du, Mater. Chem. Phys. 130, 425 (2011)

[63] S. Tewari, A. Bhattacharjee, Pramana 76, 153 (2011).

[64] K.-S. Jeon, S.-D. Oh, Y.D. Suh, H. Yoshikawa, H. Masuhara, M. Yoon, Phys. Chem. Chem. Phys. 11, 534 (2009).

[65] C. Persson, C. Platzer-Björkman, J. Malmström, T. Törndahl, M. Edoff, Phys. Rev. Lett. 97, 146403 (2006).

[66] O. Lupan, T. Pauporté, L. Chow, B. Viana, F. Pellé, L. Ono, B.R. Cuenya, H. Heinrich, Appl. Surf. Sci. 256, 1895 (2010).

[67] Y. Yan, M. Al-Jassim, S.-H. Wei, Appl. Phys. Lett. 89, 181912 (2006).

[68] M. Fu, Y. Li, P. Lu, J. Liu, F. Dong, Appl. Surf. Sci. 258, 1587 (2011). 